\title{
Characterization of the Inflammatory Infiltrate in Streptococcus pneumoniae Pneumonia in Young and Elderly Patients
}

\author{
Thomas Menter $^{\mathrm{a}}$ Carmen Giefing-Kroell ${ }^{\mathrm{b}}$ Beatrix Grubeck-Loebenstein ${ }^{\mathrm{b}}$ \\ Alexandar Tzankov ${ }^{a}$ \\ anstitute of Pathology, University Hospital, Basel, Switzerland; ${ }^{b}$ Institute of Biomedical Ageing Research, \\ Austrian Academy of Sciences, Innsbruck, Austria
}

\section{Key Words}

Streptococcus pneumoniae pneumonia $\cdot$ Inflammatory infiltrate · Lymphocytes · Granulocytes · Macrophages

\begin{abstract}
There is an increased susceptibility and mortality in the elderly due to pneumonia caused by Streptococcus pneumoniae. We aimed to assess the inflammatory cell composition with respect to age in pneumococcal pneumonia patients. Neutrophilic granulocytes and various lymphocyte and macrophage subpopulations were immunohistochemically quantified on lung tissue specimens of young $(n=5$; mean age 8.4 years), middle-aged ( $n=8$; mean age 55.9 years) and elderly ( $n=9$; mean age 86.6 years) pneumonia patients with microbiologically proven S. pneumoniae pneumonia. We discovered a higher percentage of neutrophilic granulocytes in elderly as opposed to young patients ( $95 \mathrm{vs.75 \% ,p=}$ 0.012 ). Conversely, young patients versus elderly patients had more alveolar macrophages (CD11c+: 20 vs. $9 \%, p=$ 0.029 ) and $M 1$ macrophages (CD14+: 30 vs. $10 \%, p=0.012$ and HLA-DR+: 52 vs. $11 \%, p=0.019)$. There was no significant difference concerning M2 macrophages and lymphocytes. Comparison of young patients with middle-aged patients showed similar significant results for alveolar macrophages $(p=0.019)$ and subsignificant results for M1 macrophages
\end{abstract}

and neutrophilic granulocytes $(p<0.08)$. This is the first study characterizing the inflammatory infiltrate of pneumococcal pneumonia in situ. Our observations improve the understanding of the innate immune mechanisms of pneumococcal lung infection and point at the potential of therapies for restoring macrophage function and decreasing neutrophilic influx in order to help prevent or cure pneumonia.

(c) 2014 S. Karger AG, Basel

\section{Introduction}

Pneumonia caused by Streptococcus pneumoniae is still a major health problem, especially amongst young children and the elderly. It accounts for 1.6 million deaths worldwide; 1 million of these are children, mainly in developing countries [1]. In a cohort of 18,000 patients from Denmark, the mortality rate for adults older than 65 years was $24 \%$ compared to $14 \%$ for individuals aged $15-65$ years [2]. This increased susceptibility of the elderly is largely explained by the aging of organ systems and the presence of comorbidities [3]. Other important risk factors beside age include multilobar involvement, shock, assisted ventilation, need of intensive care, chronic heart failure, renal failure, preexisting pulmonary disorders, immunosuppression and other serious underlying diseases [1].

\section{KARGER}

E-Mail karger@karger.com www.karger.com/pat (c) 2014 S. Karger AG, Base

1015-2008/14/0813-0160\$39.50/0
Prof Dr. med Alexandar Tzankov

Institute of Pathology

Schönbeinstrasse 40

$\mathrm{CH}-4031$ Basel (Switzerland)

E-Mail alexandar.tzankov@usb.ch 
Since the introduction of a conjugated polysaccharidebased vaccine, the incidence of pneumococcal diseases has declined significantly in immunized children [4]. In contrast to the high efficacy of vaccinations in children, the results in the elderly have not been as clear-cut [5]. Randomized trials have generally failed to demonstrate that polysaccharide vaccines reduce all-cause [5] or pneumococcal pneumonia [6-8] in the elderly, suggesting suboptimal efficacy in preventing pneumococcal pneumonia, the typical manifestation of pneumococcal disease in this age group.

The innate immune defense mechanisms against pneumococci during lung infection are made up of several factors such as resident alveolar macrophages, infiltrating neutrophils, complement and CD4+ T cells (reviewed by Kadioglu and Andrew [9]). Due to the efficacy of serum therapy and polysaccharide-based vaccines, anticapsular antibodies were previously thought to be the main mechanism of acquired adaptive immunity to pneumococcal disease $[10,11]$. More recent studies showed the acquisition of serotype- and antibody-independent immunity with age, so the involvement of alternative mechanisms, dependent on T helper (Th) cells, was proposed $[12,13]$. Several researchers have demonstrated that protection against pneumococcal carriage requires the presence of $\mathrm{CD} 4+\mathrm{T}$ cells and that the Th17 signature cytokine interleukin (IL)-17 plays a major role in defense against pneumococci [14, 15]. In the search for the cause of increased susceptibility in the elderly, Schmid et al. [16] discovered that the IgG levels specific for certain pneumococcal proteins decline with age but that the percentage of cytokine-secreting donors remains unchanged. They could demonstrate that IL-17A production was most often accompanied by interferon $\gamma$ or a combined response of interferon $\gamma$ and IL-5 in the young and middle-aged, but rarely in the elderly. Natural exposure to pneumococci seemed to induce both Th17 and Th1 responses in the young and middle-aged, but in the majority of elderly subjects, only a Th17 or a Th1 response. Recently, in vitro coculture studies of human monocytes and CD4+ Th cells showed a mixed Th1/Th17 response with a primarily Th1-based response triggered by living bacteria and a primarily Th17-based response to heat-killed bacteria [17]. These data could confirm earlier studies conducted in mice [15].

Macrophages appear to be of considerable importance in immunomodulation and in the priming of the immune response [18], yet their role in bacterial infection has not been fully elucidated. A recent review by Aberdein et al.
[19] emphasizes the impact of alveolar macrophages on primary host defense against $S$. pneumoniae in preventing the manifestation of pneumonia. Macrophages are generally divided into 2 groups, M1 and M2 macrophages, described primarily in the inflammatory infiltrate of carcinomas [20]. However, the alveolar macrophages seem to not fit perfectly into this scheme. Duan et al. [21] showed that alveolar macrophages could be divided by flow cytometry into distinct subgroups, depending on whether the mice in their study showed acute inflammation or chronic lung disease.

In this study, we evaluated the composition of the inflammatory infiltrate in young, middle-aged and elderly patients in order to gain new in situ and in vivo insights into the age-dependent inflammatory antipneumococcal response. We correlated our findings with the data available from serological and in vitro studies in the literature. We focused specifically on the role of alveolar and M1/ M2 macrophages.

\section{Material and Methods}

\section{Patient Selection}

We selected patients with microbiologically proven pneumococcal pneumonia from our archive. They consisted of individuals younger than 30 years $(n=5)$, middle-aged patients (i.e. between 30 and 70 years of age; $n=8)$ and patients older than 70 years $(n=$ 9). The pneumonic infiltrates were classified as exsudative (fibrin and granulocyte-rich), resorptive (histiocyte-rich), organizing (connective-tissue-rich) and mixed patterns. The available clinical information of the patients was retrieved from our files. Patient characteristics are listed in table 1.

A group consisting of both young and elderly patients $(n=10$; median ages 25.6 and 65.3 years, respectively; 7 males and 3 females), treated with partial lung resection for pneumothoraces without evidence of inflammatory bacterial diseases, was used as a control group to describe the inflammatory cells found in nonpneumonic lung tissue.

\section{Immunohistochemistry}

The antibodies and conditions of the immunohistochemical staining for characterizing the inflammatory infiltrate are listed in table 2. One full mounted slide from each patient was used for evaluation. To establish the respective antibodies, proper positive ( $\mathrm{T}$ and $\mathrm{B}$ cell lymphomas, acute monoblastic leukemias, hairy cell leukemias and histiocytic and dendritic cell sarcomas) and negative controls (central nervous tissue devoid of inflammation) were established and experiments that omitted the primary antibodies and applied irrelevant antibodies were performed.

\section{Evaluation of Stainings}

All the available lung slides of the patients were reviewed. The slide with the most prominent inflammatory infiltrate was used for immunohistochemical evaluation. The stained slides were evaluated 
Table 1. Patient characteristics

\begin{tabular}{|c|c|c|c|}
\hline Number & 5 & 8 & 9 \\
\hline Male/female & $0 / 5$ & $6 / 2$ & $5 / 4$ \\
\hline Biopsy cases & 3 & 0 & 0 \\
\hline Stage of pneumonia & $\begin{array}{l}\text { exsudative stage }(4 / 5) \\
\text { exsudative with organization } \\
(1 / 5)\end{array}$ & $\begin{array}{l}\text { exsudative stage }(6 / 8) \\
\text { exsudative with organization } \\
(2 / 8)\end{array}$ & $\begin{array}{l}\text { exsudative stage }(8 / 9) \\
\text { exsudative with organization }(1 / 9)\end{array}$ \\
\hline Known comorbidities & $\begin{array}{l}\text { encephalitis due to Varicella } \\
\text { virus, primary manifestation } \\
\text { of diabetes mellitus type } 1 \\
(1 / 5) \\
\text { asthma }(1 / 5)\end{array}$ & $\begin{array}{l}\text { alcohol abuse }(4 / 8) \\
\text { history of smoking }(2 / 8)\end{array}$ & $\begin{array}{l}\text { diabetes mellitus type } 2(1 / 9) \\
\text { dementia }(3 / 9) \\
\text { lung cancer }(1 / 9) \\
\text { breast cancer }(1 / 9) \\
\text { diffuse large B cell lymphoma (1/9) } \\
\text { alcohol abuse }(1 / 9) \\
\text { history of smoking }(1 / 9) \\
\text { heart amyloidosis }(1 / 9)\end{array}$ \\
\hline Cause of death & $\begin{array}{l}\text { pneumonia }(1 / 2) \\
\text { cerebral edema and severe } \\
\text { pneumonia }(1 / 2)\end{array}$ & pneumonia $(8 / 8)$ & pneumonia (9/9) \\
\hline Mechanical ventilation & 1 & 0 & 0 \\
\hline $\begin{array}{l}\text { Time between diagnosis of } \\
\text { pneumonia and death, days }\end{array}$ & $2-14$ & $1-23$ & $0-30$ \\
\hline
\end{tabular}

Table 2. Antibodies for immunohistochemistry

\begin{tabular}{lllll}
\hline Antibody & Source & Dilution/incubation & Retrieval & Detection \\
\hline CD3 & Ventana 790-4341 & prediluted & CC1 (Benchmark XT) & DAB \\
CD4 & Ventana 790-4423 & prediluted & CC1 (Benchmark XT) & DAB \\
CD8 & Ventana 790-4460 & prediluted & CC1 (Benchmark XT) & DAB \\
CD11c & Leica PA0554 & prediluted & CC1 (Benchmark XT) & DAB \\
CD14 & Ventana 760-4523 & prediluted & CC1 (Benchmark XT) & DAB \\
CD15 & Ventana 760-2504 & prediluted & CC1 (Benchmark XT) & DAB \\
CD20 & Dako IR604 & prediluted, A/B block & CC1 mild (Benchmark XT) & DAB \\
CD163 & Ventana 760-4437 & prediluted & CC1 mild (Benchmark XT) & DAB \\
HLA-DR & Dako M0775 & $1: 50$ & CC1 (Benchmark XT) & DAB \\
\hline
\end{tabular}

by two pathologists (T.M. and A.T.) to study agreement between observers. The inflammatory infiltrate in the areas of pneumonia was assessed. The number of positive cells was estimated as a relative percentage of the whole infiltrate. Unspecific stainings in the erythrocytes and lung parenchyma as well as areas of necrosis and those containing a lot of debris were taken out for the purpose of the evaluation.

\section{Statistical Analysis}

The degree of agreement between observers was evaluated by interclass correlation coefficients, using analysis with Cronbach's alpha statistic for reliability: $\alpha>0.75$ was generally considered to be well-reproducible. Correlation analysis of clinicopathological (e.g. age, sex and histological pattern) and immunohistochemical parameters was performed using the Fisher's exact test. In addi- 
Table 3. Summary of immunohistochemical staining results expressed as a mean percentage (range)

\begin{tabular}{llccc}
\hline Marker & Young cohort & Middle-aged cohort & Elderly cohort & p value ${ }^{\text {Kruskal-Wallis H }}$ \\
\hline CD3 & $4.5(0.5-10)$ & $1(0.5-2)$ & $1.6(0.5-5)$ & 0.086 \\
CD4 & $3.9(0.5-10)$ & $1.2(0.5-5)$ & $1.1(0.5-3)$ & 0.111 \\
CD8 & $5.8(1-15)$ & $1.6(0.5-3)$ & $2.1(1-4)$ & 0.480 \\
CD20 & $2.5(0.5-5)$ & $0.6(0.5-1)$ & $0.6(0.5-1)$ & 0.082 \\
CD15 & $75(50-95)$ & $90.6(70-95)$ & $94.5(90-95)$ & 0.007 \\
CD11c & $20(10-30)$ & $7(1-15)$ & $8.8(1-20)$ & 0.031 \\
CD14 & $30(10-50)$ & $13.5(5-30)$ & $10(5-15)$ & 0.025 \\
CD163 & $40(10-70)$ & $16.3(5-30)$ & $15.7(8-25)$ & 0.145 \\
HLA-DR & $52(25-80)$ & $17.5(5-10)$ & $11.4(5-20)$ & 0.043 \\
\hline
\end{tabular}

tion, the mean percentage of positively stained cells was compared, significant markers were corrected for multiple testing $\left(\mathrm{p}^{\text {ANOVA }}<\right.$ 0.005 ) and were further analyzed using the Kruskall-Wallis test when all 3 age groups were considered or the Mann-Whitney $\mathrm{U}$ test when the age groups were compared in pairs, respectively. Two-sided tests were used throughout. $\mathrm{p}<0.05$ was considered significant. Statistical calculations were performed using SPSS 22.0 software (SPSS, Chicago, Ill., USA).

\section{Results}

\section{Characterization of the Inflammatory Infiltrate}

Cronbach's alpha statistic for interobserver reproducibility of the immunohistochemical markers was excellent (highest: $\alpha=0.92$ for CD20 and lowest: $\alpha=0.78$ for CD4). The results are summarized in table 3.

\section{Lymphocytes}

The proportion of lymphocytes in the inflammatory infiltrate was low compared to that of macrophages and granulocytes (mean values were between 0.6 and $5.8 \%$ ). No statistically significant differences were seen in the distribution of either B lymphocytes detected by CD20 or T lymphocytes detected by CD3. There was also no difference in the subsets of cytotoxic and Th cell equivalents according to the amount and distribution of CD4+ and $\mathrm{CD} 8+$ cells and the CD4/CD8 ratio. Due to the low percentage of $\mathrm{T}$ cells, these were not further subtyped.

\section{Granulocytes}

The share of neutrophilic granulocytes detected by CD15-staining was significantly higher in the cohort of elderly patients than in the cohort of young patients (mean value 94.5 vs. $75.0 \%$, respectively, $\mathrm{p}=0.003$; fig. 1 ). The difference between middle-aged and young patients was not yet significant $(\mathrm{p}=0.075)$.

Characterization of the Inflammatory

Infiltrate in S. pneumoniae Pneumonia

\section{Macrophages}

Macrophages were investigated by a panel consisting of CD11c, CD14, CD163 and HLA-DR (fig. 1). CD11c is used to stain alveolar macrophages [22] and CD14 and HLA-DR are markers of M1 macrophages [23]. HLA-DR has been shown to be upregulated in the macrophages of patients with pneumonia [24]. CD163 is a marker for M2 macrophages [25]. We observed that macrophages were significantly more numerous in the young than in the elderly patients (CD14: mean value 30.0 vs. $10.0 \%$, respectively, $\mathrm{p}=0.011$; HLA-DR: mean value 52.0 vs. $11.4 \%$, respectively, $p=0.018$ ). Specifically, there was an enrichment of alveolar macrophages (CD11c: mean value 20.0 vs. $8.8 \%, \mathrm{p}=0.030$ ). The mean amount of CD163-positive cells was higher in the young patients (table 3 ), but there was no statistically significant difference between the groups of young and elderly patients for this M2 marker.

With regard to the inflammatory infiltrate, there were no statistically significant differences between the middleaged and elderly patients. When comparing young and middle-aged patients, there was a significantly higher percentage of alveolar macrophages in the former (CD11c: mean value 20 vs. $7 \%$, respectively, $p=0.019)$. For M1 macrophages, the differences were subsignificant $(\mathrm{CD} 14 \mathrm{p}=$ 0.054; HLA-DR $p=0.074$; fig. 2). Combining the middleaged and elderly patients and comparing them to the young patients, there was a significant difference in the number of CD15+ neutrophilic granulocytes $(\mathrm{p}=0.005), \mathrm{CD} 11 \mathrm{c}+$ alveolar macrophages $(\mathrm{p}=0.01)$ and M1 macrophages (HLA$\mathrm{DR} p=0.019 ; \mathrm{CD} 14 \mathrm{p}=0.012$ ), which replicated the results of the comparison of young patients with elderly patients.

\section{Pneumonia Pattern}

In all the cases, the pneumonia was in the exsudative stage. One young patient, 2 middle-aged patients and 1 elderly patient already showed focal signs of organization, 

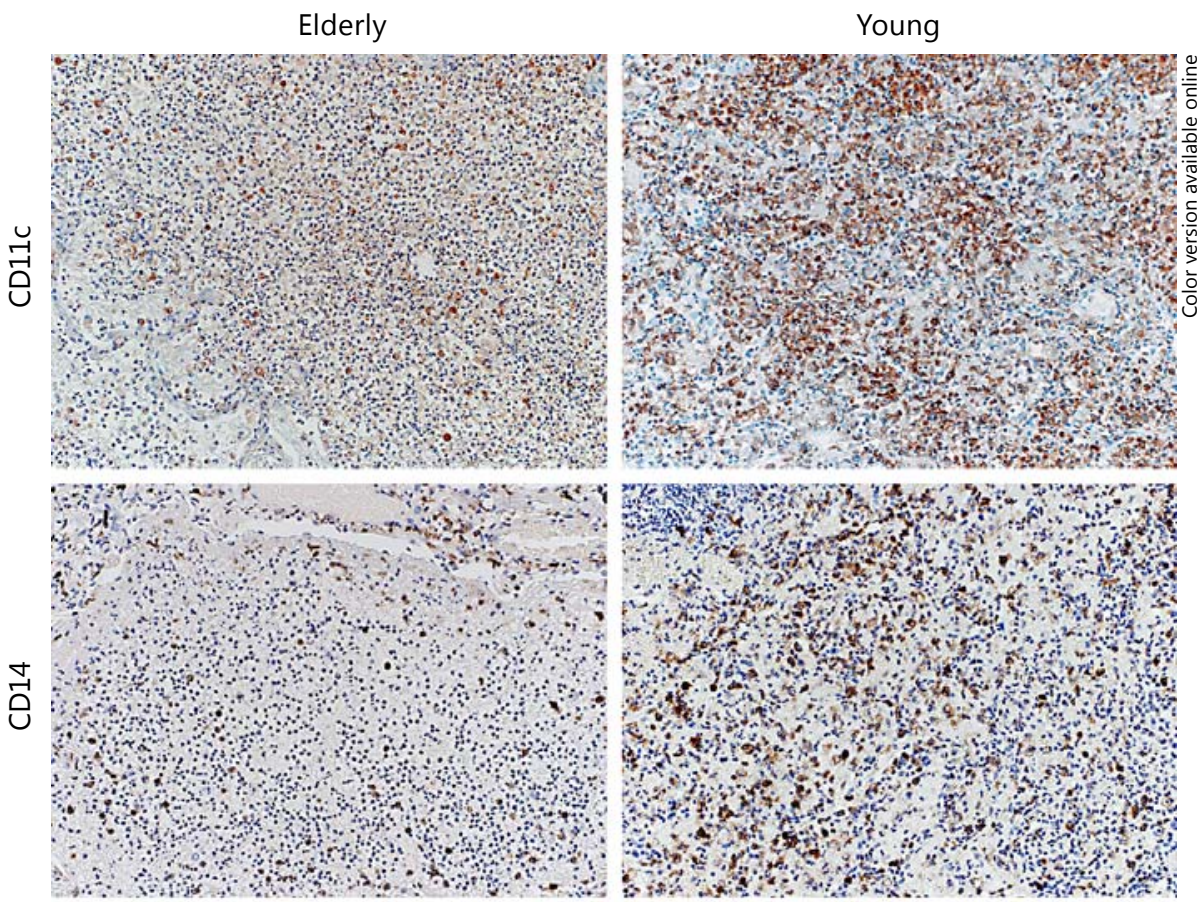

Fig. 1. Stainings for CD11c/alveolar macrophages (top row), CD14/macrophages (second row), CD15/neutrophilic granulocytes (third row), CD163/M2 macrophages (fourth row) and HLA-DR/M1 macrophages (bottom row) in elderly (left column) and young patients (right column). Immunoperoxidase. $\times 200$.
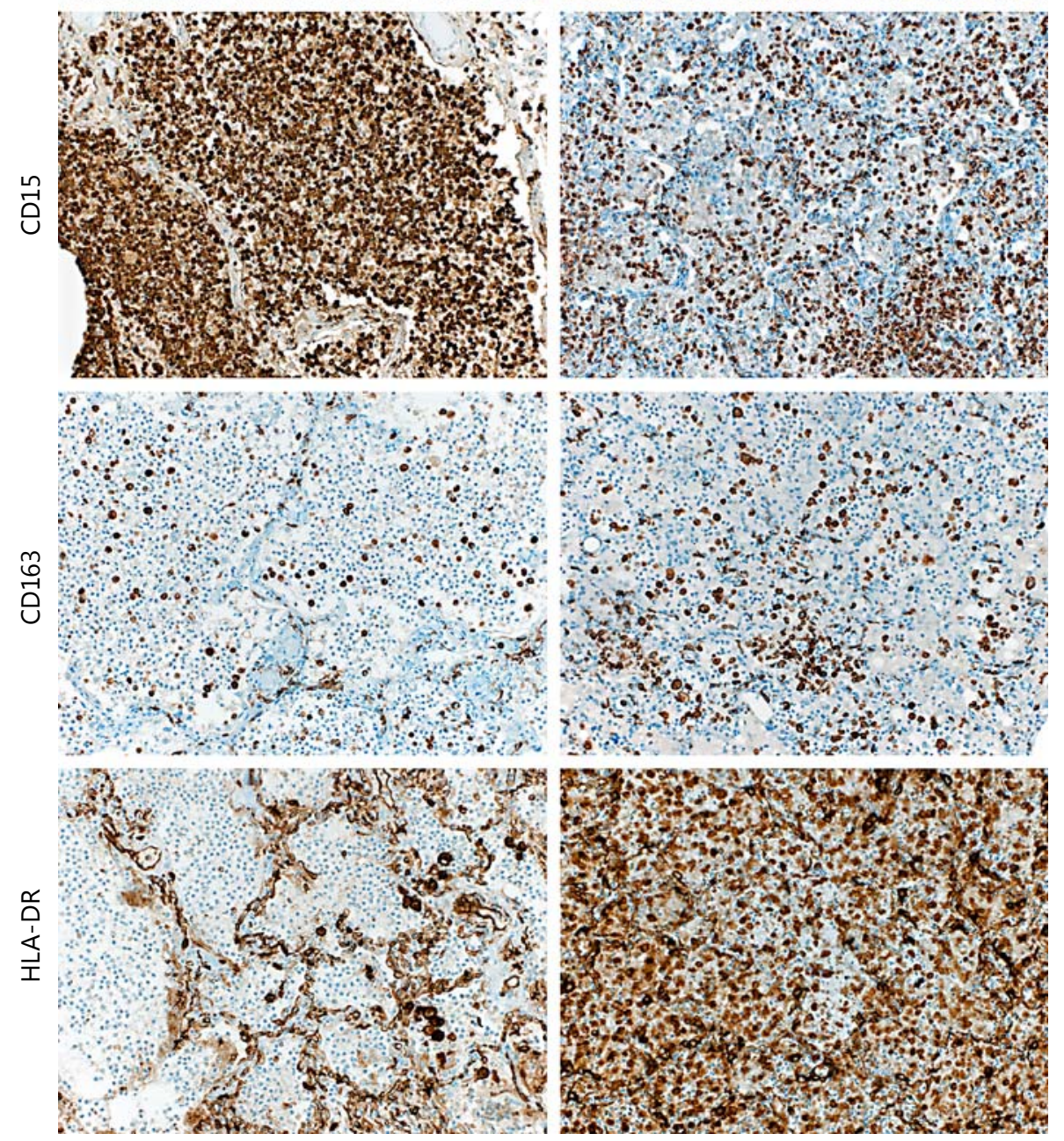

Menter/Giefing-Kroell/

Grubeck-Loebenstein/Tzankov 


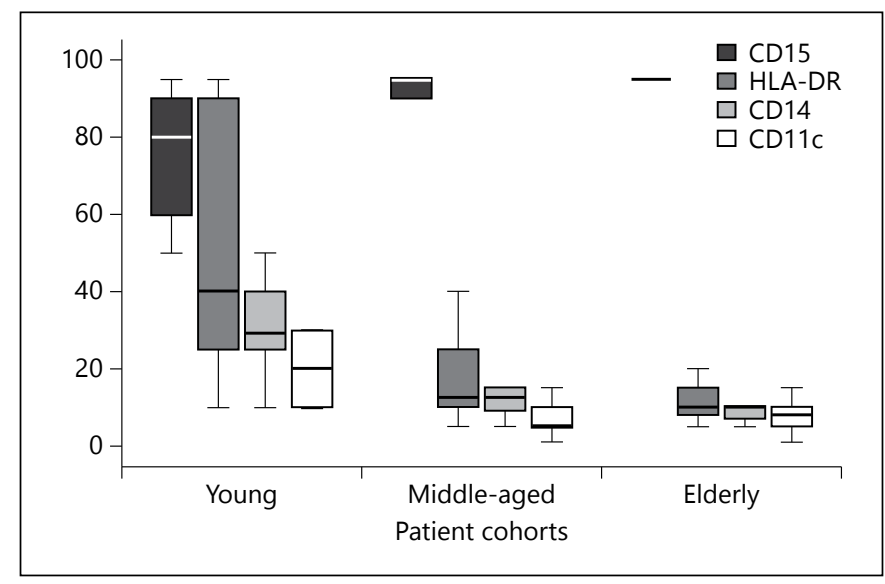

Fig. 2. Boxplots show the distribution of cellular populations with respect to the age of the patients. The Mann-Whitney $U$ test showed significant differences for CD15 between young and elderly patients $(p=0.012)$, for CD11c between young and elderly patients $(\mathrm{p}=0.029)$ and between young and middle-aged patients $(\mathrm{p}=0.019)$, for CD14 between young and elderly patients $(\mathrm{p}=$ 0.012 ) and for HLA-DR between young and elderly patients ( $\mathrm{p}=$ $0.019)$.

while focal diffuse alveolar damage and prominent fibrin exsudations were still observable. One elderly patient showed focal abscess formation. There were no statistical differences between groups in pneumonia pattern or inflammatory cell composition.

\section{Inflammatory Infiltrate of the Control Group}

The inflammatory cells in the control group consisted predominantly of B and T lymphocytes with few macrophages and very sparse granulocytes. There was no difference in the composition of the inflammatory cells between the elderly and young patients in the control group.

\section{Discussion}

We discovered that the inflammatory infiltrate of the elderly patients contained a higher percentage of neutrophilic granulocytes when compared to the young patients. Our findings correlate with data from Meyer et al. [26], who observed that the percentage of neutrophils and the level of IL-8 increased with age in bronchoalveolar lavage fluid samples from young, middle-aged and elderly healthy non-smokers. A reduced defense capacity of neutrophils, due to a decrease in Toll-like receptor-mediated activation, phagocytic ability (particularly Fc receptor-mediated), oxidative burst and the ability to respond

Characterization of the Inflammatory

Infiltrate in S. pneumoniae Pneumonia to survival factors (e.g. granulocyte macrophage colonystimulating factor and granulocyte colony-stimulating factor) at the site of inflammation is supposed to lead to decreased resistance to (bacterial) infections in the elderly, despite the increase in the number of granulocytes at these sites [27, 28].

We found a higher percentage of both alveolar and M1 macrophages in the young patients. In general, macrophages display a reduced phagocytic capacity and impaired oxidative burst in elderly people $[29,30]$. Furthermore, defects in the upregulation of MHC class II molecules (as observed for HLA-DR in our study) and the expression of Toll-like receptors have been shown in macrophages in elderly people [29]; this hampers success in fighting infection as well as the efficacy of vaccinations [30]. Impaired monocyte/macrophage function results in failure to eliminate pathogens and prolongs their survival in cells (e.g. tuberculosis). This is accompanied by chronic activation of the innate immune system, leading to persistent inflammation $[28,31]$. The M1 program of macrophages, such as that observed in the young patients, is usually associated with protection during acute infectious diseases. However, an excessive or prolonged M1 program may also be deleterious for the host, as observed in infections with Escherichia and Streptococcus species [32]. Alveolar macrophages form a distinct entity in the family of macrophages. As residual macrophages of the lung, they are capable of phagocytosis of pathogens as well as T cell recruitment in the early phase of infection [33]. Murine studies have shown that depletion of alveolar macrophages increases the susceptibility of mice to pneumonia and leads to a more aggressive disease course [34]. A decrease in the number of alveolar macrophages at the site of inflammation in elderly patients, as detected in our study, might contribute to the increased susceptibility of this age group for pneumonia. Put together, our data allow us to create a hypothetical scenario: in the absence of sufficient numbers of alveolar and M1 macrophages for fighting the infection in elderly patients there could be a compensatory massive infiltration of neutrophilic granulocytes, which leads to enhanced tissue destruction. The changes observed in young and elderly patients were thought to be similar. When looking at the middle-aged patients, this was not as clear (fig. 2), but there was already a significant decrease in alveolar macrophages in this age group; this argues for a decrease in macrophage numbers (and possibly function) in the course of a lifetime.

Our study has some shortcomings, i.e. the small number of investigated cases and the lack of more comprehen- 
sive clinical data. This is due to the scarcity of young patients dying from pneumonia or being partially pneumonectomized for microbiologically proven pneumonia. Due to our strict inclusion criterion of microbiologically proven pneumococcal pneumonia, only females were found for the young patient group. It is important to note here that there are studies demonstrating a gender-specific difference concerning the reaction to pneumococcal lung infection, at least in infants $[35,36]$. These studies show that male infants are more prone to pneumonia than female infants, but that this is not the case in adolescents [35]. Considering the female predominance in our infants' collective, one may speculate that there was at least no selection bias towards poor-prognosis patients in our cohort of young individuals. Finally, although no differences in CD4+ T cells were observed in our analysis, there may have been age-related differences in Th1/Th17 subsets, as observed in the periphery. However, due to the low percentage of $\mathrm{T}$ cells, subset studies were not considered feasible.

\section{Conclusions}

This is the first study characterizing the inflammatory infiltrate of pneumococcal pneumonia in situ. In accordance with earlier in vitro and serological studies, we could show a reduced macrophage response accompanied by an increase of neutrophilic granulocytes in elderly patients. The proportion of alveolar and M1 macrophages, in particular, was significantly lower in elderly patients. Thus, our study contributes to a better understanding of the innate response mechanisms to pneumococcal infection in the lung. Studies on nursing-home patients have shown that supplementation with zinc, which plays an important role in macrophage function, could reduce the incidence of pneumonia [37]. Other therapeutic options such as the application of cytokines have also been suggested previously [38]. In summary, restoring macrophage function and decreasing neutrophilic influx in the elderly might be crucial for reducing the burden of pneumonia in this age group.

\section{References}

1 Lynch JP 3rd, Zhanel GG: Streptococcus pneumoniae: epidemiology, risk factors, and strategies for prevention. Semin Respir Crit Care Med 2009;30:189-209.

- 2 Harboe ZB, Thomsen RW, Riis A, Valentiner-Branth P, Christensen JJ, Lambertsen L, Krogfelt KA, Konradsen HB, Benfield TL: Pneumococcal serotypes and mortality following invasive pneumococcal disease: a population-based cohort study. PLoS Med 2009, 6:e1000081.

- 3 Janssens JP, Krause KH: Pneumonia in the very old. Lancet Infect Dis 2004;4:112-124.

4 Hsu HE, Shutt KA, Moore MR, Beall BW, Bennett NM, Craig AS, Farley MM, Jorgensen JH, Lexau CA, Petit S, Reingold A, Schaffner W, Thomas A, Whitney CG, Harrison LH: Effect of pneumococcal conjugate vaccine on pneumococcal meningitis. New Engl J Med 2009;360:244-256.

5 Jackson LA, Janoff EN: Pneumococcal vaccination of elderly adults: new paradigms for protection. Clin Infect Dis 2008;47:13281338.

6 Huss A, Scott P, Stuck AE, Trotter C, Egger M: Efficacy of pneumococcal vaccination in adults: a meta-analysis. CMAJ 2009;180:48-58.

$\checkmark 7$ Ortqvist A, Hedlund J, Burman LA, Elbel E, Hofer M, Leinonen M, Lindblad I, Sundelof B, Kalin M: Randomised trial of 23-valent pneumococcal capsular polysaccharide vaccine in prevention of pneumonia in middle-aged and elderly people. Swedish Pneumococcal Vaccination Study Group. Lancet 1998;351:399-403.
${ }_{8}$ Simberkoff MS, Cross AP, Al-Ibrahim M, Baltch AL, Geiseler PJ, Nadler J, Richmond AS, Smith RP, Schiffman G, Shepard DS, et al: Efficacy of pneumococcal vaccine in high-risk patients. Results of a Veterans Administration Cooperative Study. New Engl J Med 1986;315:1318-1327.

-9 Kadioglu A, Andrew PW: The innate immune response to pneumococcal lung infection: the untold story. Trends Immunol 2004;25:143149.

10 Lipsitch M, Whitney CG, Zell E, Kaijalainen T, Dagan R, Malley R: Are anticapsular antibodies the primary mechanism of protection against invasive pneumococcal disease? PLoS Med 2005;2:e15.

11 Musher DM, Groover JE, Rowland JM, Watson DA, Struewing JB, Baughn RE, Mufson MA: Antibody to capsular polysaccharides of Streptococcus pneumoniae: prevalence, persistence, and response to revaccination. Clin Infect Dis 1993;17:66-73.

12 Malley R, Trzcinski K, Srivastava A, Thompson CM, Anderson PW, Lipsitch M: CD4+ T cells mediate antibody-independent acquired immunity to pneumococcal colonization. Proc Natl Acad Sci USA 2005; 102:48484853.

13 Trzcinski K, Thompson C, Malley R, Lipsitch M: Antibodies to conserved pneumococcal antigens correlate with, but are not required for, protection against pneumococcal colonization induced by prior exposure in a mouse model. Infect Immun 2005;73:7043-7046.
14 Lu YJ, Gross J, Bogaert D, Finn A, Bagrade L, Zhang Q, Kolls JK, Srivastava A, Lundgren A, Forte S, Thompson CM, Harney KF, Anderson PW, Lipsitch M, Malley R: Interleukin17A mediates acquired immunity to pneumococcal colonization. PLoS Pathog 2008; 4 e1000159.

15 Zhang Z, Clarke TB, Weiser JN: Cellular effectors mediating Th17-dependent clearance of pneumococcal colonization in mice. J Clin Invest 2009;119:1899-1909.

16 Schmid P, Selak S, Keller M, Luhan B, Magyarics Z, Seidel S, Schlick P, Reinisch C, Lingnau K, Nagy E, Grubeck-Loebenstein B: Th17/ Th1 biased immunity to the pneumococcal proteins $\mathrm{PcsB}$, StkP and PsaA in adults of different age. Vaccine 2011;29:3982-3989.

17 Olliver M, Hiew J, Mellroth P, HenriquesNormark B, Bergman P: Human monocytes promote Th1 and Th17 responses to Streptococcus pneumoniae. Infect Immun 2011;79: 4210-4217.

18 Murray PJ, Wynn TA: Protective and pathogenic functions of macrophage subsets. Nat Rev Immunol 2011;11:723-737.

19 Aberdein J, Cole J, Bewley M, Dockrell DH: Alveolar macrophages in pulmonary host defence - the unrecognised role of apoptosis as a mechanism of intracellular bacterial killing. Clin Exp Immunol 2013;174:193-202.

20 Biswas SK, Mantovani A: Macrophage plasticity and interaction with lymphocyte subsets: cancer as a paradigm. Nat Immunol 2010;11:889-896. 
21 Duan M, Li WC, Vlahos R, Maxwell MJ, Anderson GP, Hibbs ML: Distinct macrophage subpopulations characterize acute infection and chronic inflammatory lung disease. J Immunol 2012;189:946-955.

22 van Rijt LS, Jung S, Kleinjan A, Vos N, Willart M, Duez C, Hoogsteden HC, Lambrecht BN: In vivo depletion of lung $\mathrm{CD} 11 \mathrm{c}+$ dendritic cells during allergen challenge abrogates the characteristic features of asthma. J Exp Med 2005;201:981-991.

23 Ziegler-Heitbrock HW, Ulevitch RJ: CD14: cell surface receptor and differentiation marker. Immunol Today 1993;14:121-125.

24 Buhling F, Ittenson A, Kaiser D, Tholert G, Hoffmann B, Reinhold D, Ansorge S, Welte T: MRP8/MRP14, CD11b and HLA-DR expression of alveolar macrophages in pneumonia. Immunol Lett 2000;71:185-190.

-25 Hogger P, Dreier J, Droste A, Buck F, Sorg C: Identification of the integral membrane protein RM3/1 on human monocytes as a glucocorticoid-inducible member of the scavenger receptor cysteine-rich family (CD163). J Immunol 1998;161:1883-1890.

-26 Meyer KC, Rosenthal NS, Soergel P, Peterson $\mathrm{K}$ : Neutrophils and low-grade inflammation in the seemingly normal aging human lung. Mech Ageing Dev 1998;104:169-181.
27 Lord JM, Butcher S, Killampali V, Lascelles D, Salmon M: Neutrophil ageing and immunesenescence. Mech Ageing Dev 2001;122: 1521-1535.

28 Shaw AC, Joshi S, Greenwood H, Panda A, Lord JM: Aging of the innate immune system. Curr Opin Immunol 2010;22:507-513.

29 Gomez CR, Nomellini V, Faunce DE, Kovacs EJ: Innate immunity and aging. Exp Gerontol 2008;43:718-728.

30 Weinberger B, Herndler-Brandstetter D, Schwanninger A, Weiskopf D, Grubeck-Loebenstein B: Biology of immune responses to vaccines in elderly persons. Clin Infect Dis 2008;46:1078-1084.

31 Franceschi C, Bonafe M, Valensin S, Olivieri F, De Luca M, Ottaviani E, De Benedictis G Inflamm-aging. An evolutionary perspective on immunosenescence. Ann NY Acad Sci 2000;908:244-254.

32 Benoit M, Desnues B, Mege JL: Macrophage polarization in bacterial infections. J Immunol 2008; 181:3733-3739.
Shibata Y, Berclaz PY, Chroneos ZC, Yoshida M, Whitsett JA, Trapnell BC: GM-CSF regulates alveolar macrophage differentiation and innate immunity in the lung through PU.1. Immunity 2001;15:557-567.

34 Dockrell DH, Marriott HM, Prince LR, Ridger VC, Ince PG, Hellewell PG, Whyte MK: Alveolar macrophage apoptosis contributes to pneumococcal clearance in a resolving model of pulmonary infection. J Immunol 2003;171: 5380-5388.

35 Jensen-Fangel S, Mohey R, Johnsen SP, Andersen PL, Sorensen HT, Ostergaard L: Gender differences in hospitalization rates for respiratory tract infections in Danish youth. Scand J Infect Dis 2004;36:31-36.

-36 Falagas ME, Mourtzoukou EG, Vardakas KZ: Sex differences in the incidence and severity of respiratory tract infections. Respir Med 2007;101:1845-1863.

37 Meydani SN, Barnett JB, Dallal GE, Fine BC, Jacques PF, Leka LS, Hamer DH: Serum zinc and pneumonia in nursing home elderly. Am J Clin Nutr 2007;86:1167-1173.

-38 Stout RD, Suttles J: Immunosenescence and macrophage functional plasticity: dysregulation of macrophage function by age-associated microenvironmental changes. Immunol Rev 2005;205:60-71. 